\title{
Endemias e Meio Ambiente no Século XXI
}

\section{Endemics and the Environment in the $21^{\text {st }}$ Century}

\author{
José R. Coura'
}

COURA, J. R. Endemics and the Environment in the $21^{\text {st }}$ Century Cad. Saúde Públ., Rio de Janeiro, 8 (3): 335-341, jul/set, 1992.

In the introduction the autor defines health as the "adaptation of man to environment, preserving his physical, functional, mental and social integrity". He extends the concept of development to "good living conditions, including food, housing, education, health care, social welfare, security, recreation, safety, and freedom".

The relationship between development and health is associated with natural and artificial resources and environments and with human behaviours such as population growth, crowding and migrations. Man is "Nature's host and his own victim".

Although the 1978 Alma-Ata Conference predicted "Health for all by the year 2000", the world's health deteriorated in the last decade because of the economic crisis and a population increase of about one billion persons that could not be matched by senices such as health. education, transportation, food, housing and social security.

Infectious diseases are responsible for $34 \%$ of deaths in the developing world and only $1 \%$ in developed countries. Yearly, 15 million children die from infectious diseases and/or malnutrition and $93 \%$ of avoidable deaths occur in the developing countries. There is no direct correlation between economic development and health quality; it depends on health and social organization.

Keywords: Health; Development; Environment; Endemic Diseases; Morbi-Mortality

O homem vive em um planeta onde ele cons. trói as suas casas e de onde ele tira o seu sustento. Na terra ele nasce e para a terra ele retorna após a sua morte. Com estas palavras quase biblicas Marti-Ibañez (1958) inicia a introdução do clássico livro "Ecologia da Doença Humana", de autoria de Jacques May (1958), onde continua:

Mentalmente o homem pode viajar pelo universo através do tempo, mas física e eferivamente ele está ligado a um ligar na terra, e qualquer modificaçāo nessa relação afeta profundamente a sua vida. Então, ele tem que se adaptar ao meio para organizar a sua existência no tempo e no espaço, porque a terra é o seu símbolo de estabilidade. Os mapas mostram a sua posiçāo no planeta e as plantas, a sua

\footnotetext{
'Departamento de Medicina Tropical do Instituto Oswaldo Cruz (Fiocruz). Avenida Brasih 4.365, Rio de Janeiro, RJ, 21045-900, Brasil.
}

localização, como o calendário e o relógio mostram a sua posição no tempo. e acrescenta:

Por milhares de anos o homem viveu uma vida "bidimensional" em um mundo tridimensional. No inicio, como a mais parada das criaturas, percorreu depois toda a terra e os mares até que um dia, tendo explorado todo o espaço horizontal, ele se decidiu a conquistar o espaço vertical. A tecnologia, abolindo distâncias, tem permitido a ele vertiginosas jornadas arravés do espaço cósmico, mas pela sıra inquietude espacial o homem está pagando um preço. Su estabilidade mental e física está sendo destruida.

\section{SAÚDE E MEIO AMBIENTE}

A saúde tem sido conceituada ao longo do tempo de diversas maneiras, desde a concepção simplista do seu antônimo, ou seja, a "ausência de doença", até concep̧̧ões muito agrangentes, 
como a adotada pela Organização Mundial da Saúde, que a define como um estado de completo bem-estar físico, mental e social, e nāo apenas a ausência de doença ou enfermidade.

O conceito simplista de saúde apenas como "ausência de doença" é exclusivamente organicista, ignorando os aspectos sociais e ecológi$\cos$, de fundamental importância para o bemestar físico, mental e social. Por outro lado, a concepção da Organização Mundial da Saúde, em que pese representar uma verdadeira conquista doutrinária inexequível e inexata. Por exemplo, uma pessoa viajando em um ônibus apertado, submetida ao calor dos trópicos ou ao frio de outras latitudes, não estaria em um "completo bem-estar físico"; o jovem que brigasse com a sua namorada ou o político que tivesse perdido uma eleição não estaria em um "estado de completo bem-estar mental e social". Entretanto, seria um exagero considerá-los doentes por esses motivos; talvez, no máximo, pudéssemos considerá-los desadaptados temporariamente. Ao contrário, um indivíduo acometido recentemente de um càncer de grande potencial evolutivo poderá estar temporariamente, antes de sabê-lo, em um estado de "completo bem-estar físico, mental e social", quando na realidade é portador de uma grave doença.

Perkins (1938) define saúde como um estado de relativo equilibrio da forma e função do corpo que resulta do seu ajustamento dinâmico bem-sucedido com as forças que tendem a alterá-la, e acrescenta: não é um intercâmbio passivo entre a substância do corpo e as forças que o impelem, mas uma resposta ativa trabalhando para o seu ajustamento. Por outro lado, René Dubos (1968) diz que medicamente falando, o homem é mais um produto do seu meio do que de sua herança genética, e reforça: a sauide dos seres humanos não está determinada por suas raças, e sim pelas condições sob as quais vivem.

Embora a definição de saúde de Perkins (1938) seja bem mais realista do que a formulada pela Organização Mundial da Saúde, por considerar o componente adaptativo, ela não considera os aspectos psicossociais, enquanto a conceituação de Dubos (1968), bem mais abrangente, nega exageradamente o componente genético, tomando-se inaceitável do ponto de vista científico.
Creio que poderíamos associar a visão de "adaptação" de Perkins com a de modus vivendi de Dubos e a de integração da Organização Mundial para uma definição mais completa e realística de saúde como a "adaptação do homem ao meio, preservando a sua integridade física, funcional, mental e social". Dessa forma, além de incorporarmos as noçōes fundamentais de "adaptação" e de "preservação", substituiríamos o subjetivo "bem-estar", da Organização Mundial da Saúde, por "integridade" (Coura, 1991).

A saúde nos trópicos, bem como nos climas frios e temperados, depende de uma série de adaptaçōes físicas, fisiológicas, ecológicas e culturais, dentro de um aprendizado secular para a manutenção do equilibrio próprio de cada espécie, principalmente nos chamados animais de sangue quente.

Alterando o seu metabolismo, o consumo de oxigênio, a estrutura e fisiologia da pele, a mobilidade ou plasticidade vascular e os mecanismos centrais de regulação térmica, o homem perde ou ganha calor em maior ou menor quantidade dentro dos limites de sua temperatura crítica homeotérmica. Ultrapassados esses limites, ele tem que lançar mão de meios naturais ou artificiais (abrigos, banhos, ventilação, aquecimentos ou refrigeração) para o seu conforto e sobrevivencia.

O frio é um elemento discriminador por excelência, enquanto o calor e a umidade favorecem, extraordinariamente, o desenvolvimento da vida, a exuberância da fauna e da flora e, em consequiência, uma maior interação entre as diversas espécies, elevando o trópico ao grande centro dinàmico da vida (Latif, 1959).

A maior coexistência das espécies, no entanto, se, de um lado, enriquece a natureza nas regiões tropicais e subtropicais, principalmente no trópico úmido, de outro, favorece a proliferação de germes e parasitos, o desenvolvimento de reservatórios e de vetores biológicos, induzindo, em conseqüéncia, o aumento das doenças infecciosas e parasitárias chamadas metaxênicas, ou seja, aquelas que possuem reservatórios e vetores biológicos na natureza.

Max Sorre (1955), em Fundamentos Biológi$\cos$ da Geografia Humana, trata das relaçōes entre o homem e o meio e dos fatores físicos, ambientais $\mathrm{e}$ humanos (sociais, culturais $\mathrm{e}$ 
biológicos), que, em confronto com os chamados "complexos patogênicos", englobando o próprio homem e o seu hábitat, reservatórios, agentes e vetores biológicos, dificultam a colonização e reduzem a produtividade e o desenvolvimento econômico de um lado, mas aumentam a resistência do homem, que se torna forte para enfrentar e vencer as dificuldades do meio, como os sertanejos de Euclides da $\mathrm{Cu}$ nha.

Embora sejam poucas as doenças exclusivas dos trópicos, não se pode negar a existência de uma patologia tropical. $O$ inesquecível Samuel Pessoa (1960) conceituou doença tropical como "Moléstia de ocorrência frequiente nos trópicos e de observação rara, quando ainda não vistas nos países de clima temperado", enquanto Almeida Prado (1965), citado por Carlos da Silva Lacaz em sua excelente Geografia Médica do Brasil (1972), diz: Na verdade, não se pode separar a existência da doença do substrato causal que a produz; no fundo, são, portanto, as condições climáticas que fundamentam $e$ legitimam o conceito de doenças tropicais. A essa questāo de nomemclatura, acrescenta, sobrepaira sempre uma ponta de mal-contido nacionalismo.

No ano de 1926, o Professor Carlos Chagas inaugurava a Cátedra que me honra continuar na Universidade Federal do Rio de Janeiro, com estas palavras que me fascinaram a juventude, converteram-me ao estudo da Medicina Tropical e constituem, desde então, a minha bíblia profissional, porque se confirmaram ao longo dos 32 anos que a exerço: Em aspectos peculiares à nosologia dos países quentes, autorizase a sistematização de estudos que fazem assuntos da cadeira de Medicina Tropical.

O clima não constitui fator etiopatogênico direto de qualquer entidade mórbida bemdefinida, mas, por ele, a doença se transforma $e$ modifica, e dele se originam as variantes nosológicas apreciáveis nas diversas regiōes da terra.

Nos paises quentes tropicais e subtropicais, as mesmas influências cósmicas, as mesmas energias criadoras que estimulam e favorecem a vida animal e vegetal imprimem à patologia humana características regionais, que a definem e, assim, alteram a feição genética da patologia cosmopolita.
A riqueza da flora e da fauna patogênicas é o fator predominante na nosologia dos paises tropicais. As espécies parasitárias, especialmente os protozoários, ai são mais abundantes $e$ apresentam modificaçōes biológicas, que, as mais das vezes, aumentam os efeitos de seu parasitismo nocivo; mas, além disso, vivem $e$ proliferam nos trópicos outras parasitas, que não prescindem das condiçōess climáticas dessas regiōes e só nelas encontram os elementos naturais indispensáveis a seu metabolismo e a sua multiplicaçāo.

As realizaçōes práticas da higiene e da medicina tropicais vieram destruir o velho preconceito de uma fatalidade climática, que se traduza na inadaptaçāo das raças originárias dos países frios e temperados d̀s regiōes mais quentes da terra.

O modelo científico vai dominando a doença nos trópicos, e assim desaparecem as restriçōes geográficas à vida sadia e à atividade humana, e desse modo se dilatam os domínios da civilização e do trabalho produtivo.

Nada restringe agora a expansão dos povos nessas regiōes fertilíssimas da terra, porque o acerto do método profilático, baseado no determinismo do contágio infectuoso, torna a vida possivel sob todas as latitudes e protege o homem contra a doença em quaisquer condiçōes climáticas (Chagas, 1926).

Em uma visão ecológica mais moderna do processo saúde/doença, podemos afirmar que ele se situa na intercessão entre as pessoas com os seus genes e comportamentos, migrações e aglomeraçōes, o meio natural - clima, recursos naturais, suprimento de água e alimentos, parasitos, reservatórios e vetores, de um lado, e, de outro, o meio artificial criado pelo próprio homem com a industrialização - máquinas e veículos, poluição do ar, da água e dos alimentos, radiaçōes e ameaças diversas; enfim, o homem é hóspede da natureza e vítima de si próprio. Segundo Goethe, a natureza nos rodeia e nos cinge; vivemos dentro dela e lhes somos estranhos; fala conosco, mas não nos revela os seus mais intimos segredos (Latif, 1959).

\section{DESENVOLVIMENTO E SAÚDE}

Quanto ao conceito de desenvolvimento, 
adoto-o no seu sentido mais amplo, da aquisição de bens e serviços que assegurem ao homem uma boa qualidade de vida em termos de alimentação e habitação, educação e saúde, trabalho e recreação, previdência e assistência social, segurança e liberdade, e não apenas o desenvolvimento econômico das naçōes, como é freqüentemente considerado (Coura, 1982).

Apesar da previsão da Conferência de AlmaAta, realizada em 1978 com a participação de 134 países, de "Saúde para Todos no ano 2000", segundo a Comissão Internacional de Pesquisa em Saúde para o Desenvolvimento (1990), a saúde do mundo piorou na última década. Embora tenha sido verificado, na conferência de avaliação realizada em Riga, também na União Soviética, em 1988, que houve uma melhora "na consciencia sobre cuidados primários de saúde", os indicadores mostram uma piora efetiva nas condiçōes de saúde. Essa piora se deve, principalmente, à crise econômica da década de 80 na América Latina, Ásia e África, onde, nos países subdesenvolvidos, o produto interno bruto caiu de quatro para $1,7 \%$ e os investimentos em saúde foram cortados em até $50 \%$. Por outro lado, o crescimento populacional, com a demanda de mais empregos, educação, saúde e outros serviços sociais, não tem sido acompanhado por esses países.

Anualmente nascem 90 milhões de pessoas no mundo e morrem 49 milhões, deixando um saldo de 41 milhões que, adicionados ao contingente de 5 bilhões já existentes, têm que ser alimentados, educados e receber cuidados de saúde e outros serviços sociais e que, em futuro próximo, irão aumentar o coeficiente reprodutivo mundial. Embora a população mundial tenha começado a decrescer desde o final da década de 70 , de um máximo de $2,3 \%$ ao ano, não se prevê que ela se estabilize antes do final do próximo século, quando atingirá 10 bilhões de pessoas portanto, o dobro da população atual. Nas próximas três décadas, é previsto um crescimento populacional da ordem de um bilhão de pessoas por década, de modo que, no final do último decênio deste século, deveremos ter uma população mundial de 6 bilhões de habitantes em demanda para os serviços de saúde, habitação, alimentação, transporte, segurança e uma boa parte para a educação.
A expectativa de vida nos países subdesenvolvidos é, em média, quase um terço menor do que nos paises industrializados, que atingem até 80 anos, como no caso do Japão e paises nórdicos da Europa, cuja vida média pode atingir até duas vezes a dos países mais pobres e desassistidos do mundo. Essa expectativa está diretamente relacionada à mortalidade infantil, que depende de fatores nutricionais e de atenção médica, social e educacional, mas não necessariamente de renda per capita, como são exemplos Cuba, Costa Rica e Chile, na América Latina, e Sri Lanka, Tailândia e Filipinas, na Ásia, que, por condiçōes políticas, ideológicas, sociais, culturais ou históricas, conseguiram melhores condições de saúde e baixa mortalidade infantil, com renda per capita modesta.

O Brasil tem hoje uma posição relativamentte confortável em relação aos seus indicadores de saúde, mas muito aquém de suas possibilidades. Com uma renda per capita de 1.810 dólares/ano, segundo fontes do Banco Mundial (1988), o nosso país tem uma expectativa de vida média de 65 anos, isto é, 15 anos menos do que nos países mais desenvolvidos, e uma mortalidade infantil ainda muito alta, de 65 por mil nascidos vivos, principalmente se comparado com o México, com renda per capita semelhante a uma mortalidade infantil de 48 por mil, e mais ainda quando comparado com países como Cuba, Costa Rica, China, Tailândia e Filipinas, com menos da metade da nossa renda per capita e com mortalidade infantil de, respectivamente, $15,18,33,41$ e 46 por mil nascidos vivos. Este fato se deve, primordialmente, à nossa política defasada nas áreas de saúde e educação e na má distribuição de renda.

Dos 49 milhões de pessoas que morrem por ano no mundo, 11 milhōes são nos países industrializados e 38 milhöes nos paises subdesenvolvidos, onde as doenças infecciosas e parasitárias são responsáveis por $34 \%$ das mortes, representando de todas as causas a primeira. Nos países subdesenvolvidos, morrem anualmente 15 milhões de crianças de doenças infecciosas e/ou má nutrição. O mais importante dos desafios que enfrentamos é que $93 \%$ das mortes evitáveis ocorrem justamente nos paises subdesenvolvidos.

Segundo o recente relatório da Comissão Intermacional de Pesquisa em Saúde para o 
Desenvolvimento (1990), as principais causas de mortalidade nos países subdesenvolvidos são, pela ordem, as doenças infecciosas e parasitárias (34\%), doenças do aparelho circulatório e diabetes (13\%), causas perinatais $(7 \%)$, câncer, injúrias e intoxicações e doenças pulmonares crônicas, com aproximadamente $5 \%$ cada uma. Em contraste, nos países industrializados, as principais causas de morte são as doenças do aparelho circulatório, o câncer, as injúrias e intoxicações e as doenças pulmonares crônicas; nesses países, as doenças infecciosas e parasitárias são responsáveis apenas por $1 \%$ das mortes.

Dos $34 \%$ de mortes por doenças infecciosas e parasitárias nos países subdesenvolvidos, $15 \%$ devem-se às doenças respiratórias agudas, inclusive sarampo e coqueluche; $10 \%$ às diarréias; quase $6 \%$ à tuberculose; e mais de $2 \%$ à malária. Aproximadamente 7 milhões de novos casos de tuberculose ocorrem anualmente no mundo, com 2,5 milhões de mortes, representando essa doença um quarto das doenças preveniveis nos paises subdesenvolvidos. Apesar de a Organização Mundial da Saúde ter lançado, em 1955, um "Programa de Erradicação da Malária", esse programa foi um verdadeiro fracasso, uma vez que temos hoje mais de 800 milhões de novos casos da doença no mundo por ano, com um milhão de mortes anuais. O fracasso foi devido, de um lado, à resistência dos plasmódios aos quimioterápicos, principalmente do $P$. falciparum à cloroquina, dos anofelinos ao DDT, e, de outro, a falhas operacionais.

A pandemia de SIDA/ADS que vem se instalando no mundo, de forma crescente, desde o início da última década, embora ainda não constitua uma das maiores causas de mortalidade entre as doenças infecciosas, do ponto de vista global, o seu potencial evolutivo, a alta letalidade, o crescimento exponencial de sua incidência e de outras infecçôes associadas, ao lado das grandes repercussōes sociais que vem trazendo, inclusive com lotação de leitos numa verdadeira avalanche, sc apresenta como um dos maiores desafios para a década em que vivemos. Para uma idéia de sua magnitude, uma pesquisa recente revelou que $50 \%$ das mulheres com idade entre 20 e 30 anos em Uganda e $20 \%$ dos neonatos eram sorologica- mente positivos para o HIV naquele país.

Os principais desafios relacionados à saúde, em geral, e às doenças infecciosas e parasitárias, em particular, a serem enfrentados no último decênio do século $\mathrm{XX}$ e primeiro do século XXI, principalmente nos países em desenvolvimento, podem ser situados em dois planos: político-administrativo e técnico-científico. No plano político-administrativo, a decisão dos governos de colocarem a saúde e educação como prioridades nacionais absolutas, traduzidas em recursos para as atenções primária, secundária e terciária à saúde, integradas em níveis horizontal (assistência plena) e vertical (campanhas de vacinação, tratamento em massa e seletivo de endemias e surtos epidêmicos, controle de vetores e reservatórios domésticos) e de educação básica da população, incluindo o componente saúde, é fundamental.

No plano técnico, são indispensáveis estudos para a otimização do desempenho dos serviços de saúde, com a maior eficiência e o menor custo possivel; utilização racional dos conhecimentos existentes na prevenção das doenças infecciosas; investimento em pesquisa para o controle de endemias; aperfeiçoamento de vacinas existentes - coqueluche, febre tifóide, cólera, meningites, tuberculose, lepra, raiva, influenza e pneumococo - e barateamento de outras, como a da hepatite B; desenvolvimento de novas vacinas para as doenças respiratórias agudas, diarréias infecciosas e doenças sexualmente transmitidas, inclusive a AIDS e doenças parasitárias como a malária, a esquistossomose $\mathrm{e}$ as leishmanioses - de difícil controle. O desenvolvimento de novos inseticidas para o controle de vetores e de drogas para o tratamento de doenças parasitárias não-existentes nos países industrializados, como a malária, a doençca de Chagas e as leishmanioses, bem como a urgência de uma vacina para o dengue e outras arboviroses, é um imperativo que cedo ou tarde terá que ser enfrenmtado pelos paises do Segundo e Terceiro Mundos.

Mais do que nunca, os investimentos em pesquisas básicas, tecnológicas e operacionais não-transferiveis em serviço de saúde são necessários no último decénio do século $\mathrm{XX}$ e primeiro do século XXI, se quisermos nos aproximar da quimera da OMS de "Saúde para Todos no Ano 2000" (OMS, 1981). 
No que se refere especificamente às doenças infecciosas e parasitárias e à medicina tropical, que atingiu os países subdesenvolvidos como primeira causa de morte, com uma taxa imoral e inaceitável em relação aos países industrializados, de 34 vezes mais, podemos vencer, em grande parte, esse desafio se aplicarmos as técnicas existentes com a vontade política de outros países já citados, com economia semelhante à nossa.

Nāo adiantam os jargōes teóricós de "Saúde para Todos no Ano $2000^{\circ}$ e de que "a saúde é um direito do povo e um dever do Estado" se não nos convencermos de que a saúde e a educação são direitos do povo e deveres do Estado e do povo, que também deve trabalhar para defender a sua saúde e colaborar para a sua educação, solidário com o Estado. Do contrário, jamais venceremos os desafios desta ou das décadas futuras.

\section{RESUMO}

\section{COURA, J. R. Endemias e Meio Ambiente} no Século XXI. Cad. Saúde Públ., Rio de Janeiro, 8 (3): 335-341, jul/set, 1992.

$\mathrm{Na}$ introdução do trabalho, o autor define saúde como a "adaptação do homem ao meio, preservando sua integridade física, funcional, mental e social". Por outro lado, amplifica o conceito de desenvolvimento como uma "boa qualidade de vida em tremos de alimentação, habitação, educação e saúde, seguridade social, recreação, segurança e liberdade". A relação entre desenvolvimento e saúde está associada com os recursos e meios naturais e artificiais e com os comportamentos da população humana, tais como crescimento populacional, aglomeração e migrações. $O$ homem é "hóspede da natureza e vítima de si próprio".

Embora a Conferência de Alma-Ata de 1978 tenha previsto "Saúde para todos no ano $2000^{\prime \prime}$, a saúde do mundo piorou na última década devido à crise econômica na América Latina, Ásia e África. Ao lado da crise econômica, o crescimento da população, de cerca de um bilhão de pessoas por década, não pôde ser acompanhado pelos serviços de saúde, educação, transporte, alimentação, habitação e seguridade social.

As doenças infecciosas são responsáveis por $34 \%$ das mortes no mundo subdesenvolvido e somente $1 \%$ nos países desenvolvidos. Anualmente, 15 milhōes de crianças morrem por doenças infecciosas e/ou má nutrição, $e$ 93\% das mortes evitáveis ocorrem exatamente nos países em desenvolvimento. Não há uma correlação direta entre desenvolvimento econômico e qualidade da saúde; ela depende da organização dos serviços sociais e de saúde.

Palavras-Chave: Saúde; Desenvolvimento; Meio Ambiente; Doenças Endêmicas; MorbiMortalidade

\section{REFERÊNCIAS BIBLIOGRÁFICAS}

CHAGAS, C., 1926. Aula inaugural proferida em 14 de setembro de 1926, no Pavilhão Miguel Couto da Faculdade Nacional de Medicina.

COURA, J. R., 1982. Saúde e Desenvolvimento do Nordeste Brasileiro. Jornal Brasileiro de Medicina, 42: 15-31.

, 1991. Desafios das Doenças Infecciosas e Parasitárias e da Medicina Tropical no Último Decênio do Século XX. Jornal Brasileiro de Medicina, 61: 14-21.

DUBOS, R., 1968. Determinants of Health and Disease in Man, Medicine and Environment. New York: Frederick A. Praeger.

HEALTH RESEARCH COMMISSION ON HEALTH RESEARCH FOR DEVELOPMENT, 1990. Essential link to equity in development. New York: Oxford University Press.

LACAZ, C. A., BARUZZI, R. C. \& SIQUEIRA JR. W., 1972. Introduçāo à Geografia Médica do Brasil. São Paulo: Ed. Blücher Ltda.

LATIF, M. B., 1959. O Homem e o Trópico. Uma Experiência Brasileira. Rio de Janeiro: Ed. Agir. MARTI-IBAÑEZ \& FOREWORD, F., 1959. Medical Geography and History. In: The Ecology of Human Disease (M. M. May), New York: MD Publications.

MAY, M. M., 1958. Ecology of Human Disease. New York: MD Publications.

ORGANIZAÇÃO MUNDIAL DA SAÚDE, 1981. Saúde para todos no ano 2000 . Pronunciamento do H. Mahler no dia Mundial da Saúde, em 7 de abril de 1981 . 
PERKINS, W. H., 1938. Cause and Prevention of Disease. Philadelphia: Lea \& Febiger.

PESSOA, S. B., 1969. Ensaios Médico-Sociais. Rio de Janeiro: Ed. Guanabara.

PRADO, A. A., 1965. Carlos Chagas e a descoberta da tripanossomíase americana. In: Um Dia Depois do Outro, São Paulo: Editora Clube do Livro.
SORRE, M., 1955. Fundamentos Biológicos de la Geografia Humana. Ensayo de una Ecologia del Hombre. Barcelona: Ed. Juventud.

THE WORLD BANK, 1988. World development report. New York: Oxford University Press. 